\title{
Cystic Fibrosis in An Infant: Presented as Pseudo Bartter Syndrome
}

\author{
Jubaida Rumana ${ }^{1 *}$ \\ Arpana Lyengar $^{2}$ \\ Mohammed Maruf-Ul-Quader ${ }^{3}$ \\ Mohammad Hanif ${ }^{4}$
}

'Department of Pediatrics \& Neonatology Bangladesh Institute of Health Sciences General Hospital Dhaka, Bangladesh.

${ }^{2}$ Department of Pediatric Nephrology St John's Medical College Hospital Bangalore, India.

${ }^{3}$ Division of Pediatric Nephrology Department of Pediatrics Chittagong Medical College Chittagong, Bangladesh.

${ }^{4}$ Department of Pediatric Nephrology Dhaka Shishu Hospital, Bangladesh.

\section{*Correspondence to:}

\section{Dr. Jubaida Rumana}

Junior Consultant Department of Pediatrics

Bangladesh Institute of Health Sciences and Hospital 125/1 Darus Salam, Mirpur 1

Dhaka-1216, Bangladesh.

Email: jubaidarumana@gmail.com

Mobile : +8801716977964

\begin{abstract}
Cystic Fibrosis (CF) can involve multiple organs although the most commonly affected systems are respiratory and gastrointestinal ones. In infancy it can also present as Pseudo Bartter Syndrome which is characterized by hyponatremic, hypochloremic, hypokalamic metabolic alkalosis without renal tubular pathology. We report a 5 month old boy who had history of recurrent episodes of dehydration due to vomiting and recurrent respiratory infection. His biochemical parameters suggestive of Pseudo Bartters Syndrome. Initial sweat chloride test was normal 16 $\mathrm{mEq} / \mathrm{L}$ whereas the repeated test revealed Sweat chloride concentration of 107 $\mathrm{mEq} / \mathrm{L}$. The cystic fibrosis mutation analysis revealed F508 del homozygosity for the Cystic Fibrosis Transmembrane Regulator (CFTR) gene. Cystic fibrosis should be always considered in any infant with metabolic alkalosis and hyponatremic hypochloremic dehydration, whether or not there are association with pulmonary and /or gastrointestinal symptoms. Early diagnosis is essential in improving the prognosis and long term survival of these children.
\end{abstract}

Key words: Cystic fibrosis; Children; Pseudo Bartters Syndrome; Metabolic Alkalosis.

\section{INTRODUCTION}

Cystic Fibrosis (CF) is the most common life limiting inherited autosomal recessive condition caused by a large number of mutations of the Cystic Fibrosis Transmembrane Regulator (CFTR) gene on chromosome 7. According to CF foundation, about 1000 new case of $\mathrm{CF}$ are diagnosed in each year. More than $70 \%$ of patients are diagnosed by age two ${ }^{1}$. Multiple organs are involved in CF like progressive lung disease, pancreatic insufficiency and increased sweat electrolyte concentration due to exocrine gland dysfunction ${ }^{2,3}$. In infancy, it presents typically with combination of failure to thrive, steatorrhea and respiratory symptoms. Less commonly, it can also present as Pseudo Bartters Syndrome (PBS) characterized by hyponatremia,hypokalamia hypochloremia and metabolic alkalosis without renal tubular pathology $y^{4,5}$. This presentation is most common in children under the age of 6 months ${ }^{6,7}$.

In this case report an infant with pseudo bartter syndrome as an initial presentation of $\mathrm{CF}$ is described. 


\section{CASE REPORT}

In mid August of 2014, a 5 month old boy was referred from other hospital to Nephrology Department of St John's Medical College, Bangalore, India. This child was admitted outside for vomiting, diarrhea and mild cough for 2 times. The baby was exclusively breast fed with poor weight gain. His prenatal, perinatal and post natal periods were uneventful. The family history was unremarkable. On physical examination the child had failure to thrive. His weight was $4.5 \mathrm{~kg}$ and height was 60 $\mathrm{cm}$. Weight for height- $\mathrm{Z}$ score:-3.8, Height for age Z score: -2 . On lung auscultations there were occasional crackles on both sides. Others examinations were normal. His past medical history was significant for previous 2 admissions; recent one was 15 days back, that time extensive laboratory work was performed. Laboratory tests were remarkable for the following values; serum sodium-116 mEq/1, serum chloride-65 mEq/1, serum potassium-3.4 mEq/1, urine potassium-16 mEq/L, and chloride- $6 \mathrm{mEq} / \mathrm{L}$. Venous blood gas analysis demonstrated metabolic alkalosis: $\mathrm{P}^{\mathrm{H}}-7.6, \mathrm{PCO}_{2}-31 \mathrm{~mm}$ of $\mathrm{Hg}, \mathrm{PO}_{2}-57 \mathrm{~mm}$ of $\mathrm{Hg}, \mathrm{HCO}_{3}-30 \mathrm{mmol} / \mathrm{L}$. The patients was noted to have mild leukocytosis with WBC of $17000 / \mathrm{mm} 3$ with $65 \%$ neutrophil predominance and the sweat chloride test which was performed by pilocarpine iontophoresis method was reported normal with chloride level of $16 \mathrm{mEq} / \mathrm{L}$. The rest of laboratory work up including blood glucose level, liver function tests, and stool exam were unremarkable. The child was given I/V fluids discharged home within 4 days and referred to St John's Hospital for further evaluations. After admission we reviewed the case thoroughly it revealed serum sodium-123 mEq/L, potassium level $2.6 \mathrm{mEq} / \mathrm{L}$, chloride level $62 \mathrm{mEq} / \mathrm{L}$, blood urea nitrogen-46 mg/dl, creatinine level- $0.5 \mathrm{mg} / \mathrm{dl}$, arterial blood gas analysis showed metabolic alkalosis, urine chloride was $12 \mathrm{meq} / \mathrm{L}$. Chest $\mathrm{x}$-ray reveals mild peribronchial thickening. The treatment was started with I/V hydration, electrolyte replacement and antibiotic therapy. Although the previous sweat test was normal repeated sweat test was again performed with same method revealed abnormal chloride concentration was $107 \mathrm{mEq} / \mathrm{L}$. Then third sweat test with CFTR mutation analysis was ordered. The cystic fibrosis mutation analysis revealed F508 del homozygosis for the CFTR gene. Cystic fibrosis was diagnosed and started treatment with pancreatic enzyme, bronchodilators and postural drainage for chest physiotherapy and sodium replacement to breast milk.

\section{DISCUSSION}

Pseudo bartter syndrome is very infrequently reported in infancy and its biochemical abnormalities are similar to those of Bartter syndrome although there was no pathology in renal tubules in pseudo bartter syndrome ${ }^{8,9}$. Pseudo bartters syndrome are caused by cystic fibrosis, surreptitious diuretic use, chronic administration of a chloride deficient diet, pyloric stenosis, continuous gastric drainage without appropriate electrolyte replacement, cyclic vomiting, congenital chloridorrhea, abuse of laxatives ${ }^{10}$.
In all this condition the chloride content of urine will be low except diuretic use and this is contrary to all forms of Bartter syndrome. In cystic fibrosis due to loss of excessive salt with sweat can cause episodes of hyponatremic, hypochloremic dehydration with metabolic alkalosis. Due to loss of salt and water also secondary hyperaldesteronism develop that increased hydrogen and potassium ions waste via the kidneys. The preceding infections and /or inadequate sodium replacement can aggravate metabolic alkalosis and electrolyte loss. It was known that the hot climate during summer months, over heated houses during winter months, over clothing cause sodium and potassium loss due to excessive sweating in infants with $\mathrm{CF}^{5}$. In our case the patient had history of recurrent admissions for vomiting, diarrhoea with electrolyte imbalance with metabolic alkalosis and failure to thrive. We can speculate that hot weather, exclusively breast feeding and intercurrent infection were contributing factors for aggravating the metabolic alkalosis in our patient. The sweat test is considered as the best test to diagnose $\mathrm{CF}$, however our patient first test was reported normal. We speculate that the false sweat chloride test was due to either inadequate sample or technical error. The cause of false negative sweat chloride test are edema due to hypoproteinemia secondary to pancreatic exocrine insufficiency, low sweat rate, inadequate sample and technical errors $^{11}$.

Severe metabolic alkalosis if not treated can cause apathy, confusion, cardiac arrhythmias and neuromuscular irritability. It also causes compensatory hypoventilation ${ }^{12}$. Therefore early diagnosis and prompt correction with I/V hydration in addition to sodium replacement and potassium replacement if necessary is crucial. Infant with CF loose large amount of sodium in their sweat. Neither human milk nor standered infant formulas provides adequate sodium for $\mathrm{CF}$ infants. CF foundation evidence based guidelines recommends $12.5 \mathrm{mEq}$ of sodium from birth to 6 months of age and $25 \mathrm{mEq}$ of sodium in the second half of first year ${ }^{13}$.

Several mutations of the CFTR gene associated with PBS were reported in literature. Our patient had F508 del homozygosity for the CFTR gene,this mutation was also described in one article (Case Report) of Catarina et $\mathrm{al}^{14}$.

\section{CONCLUSION}

We would like to emphasis a few points in this case reports, we should consider $\mathrm{CF}$ in a patient with hyponatremic, hypochloremic, hypokalamic dehydration and metabolic alkalosis especially in infants and be aware of the possibility of getting false negative result of sweat test. If the clinical presentations of the patient are consistent with $\mathrm{CF}$ we should insist for another sweat test and consider mutation analysis.

\section{DISCLOSURE}

All the authors declared no competing interest. 


\section{REFERENCES}

1. Cystic Fibrosis Foundation. About Cystic Fibrosis. Available online athttp://www.cff.org/about cf (Retrieved December 2013).

2. Boat TF. Cystic Fibrosis. In: Kliegman RM,Stanton BMD, Geme J,Schor NF,Behrman RE. Nelson Textbook of Pediatrics. Philadelphia:WB Saunders, 2012;19:1437-1450.

3. Garry R Cutting,Pamela L.Zeitlin.Genetics and pathophysiology of cystic fibrosis. In: Chernick V, Boat TF, Wilmott RW, Bush A, eds. Kendig's Disorders of the Respiratory Tract in Children. Philadelphia: Elsevier. 2012; (8).

4. Yalcin E,Kipper N,Dogru d,Ozcelik U,Aslan AT.Clinical features and treatment approaches in cystic fibrosis with pseudo barter syndrome.Ann Trop Paedatr. 2005; 25:119-124.

5. Fustic S,Jar danova-Pop N, Slaveska N, Koceva S, Efremov G. Metabolic alkalosis with hypoelectrolytemia in infants with cystic fibrosis. Pediatric international. 2002; 44:289-292.

6. Bates CM, Baum M, Quigley R. Cystic fibrosis presenting with hypokalemia and metabolic alkalosis in a previously healthy adolescent. J Am Soc Nephrol. 1997; 8(2):352-355.

7. Sojo A, Rodriguez-SorianoJ, Vitoria JC, Vazquez C, Ariceta G, Villate A. Chloride deficiency as a presentation or complication of cystic fibrosis. Eur J Pediatr. 1994;153(11):825 • 828.

8. Kennedy JD, Dinwiddie R, Daman-Willems C, Dillon MJ,Matthew DJ.Pseudo Bartters Syndrome in cystic fibrosis arch Dis Child.1990;65:786-587.

9. $\quad$ Amirlak I, Dawson KP. Bartter syndrome: An overview. QJ Med.2002; 93:207-215.

10. Ozdogan S, Atli B, Kizilkan NU. Pseudo Bartter syndrome in an infant :As a presentation of Cystic fibrosis.case study and Case report. 2014;4(2):49-53

11. Avantika Mishra, Ronda Greaves, John Massie. The relevance of sweat testing for diagnosis of cystic fibrosis in the genomic era. Clin Biochem Rev.2007;28: 60-76.

12. Galla JH.Metabolic alkalosis.J Am Soc Nephro. 2000; 11: 369-375.

13. Borowitz D, Robinson KA,Rosenfeld M,Davis SD.Cystic Fibrosis Foundation evidence based guidelines for management ofinfants with Cystic Fibrosis.J Pediatr.2009 ; 155 (6 suppl)73-93.

14. Catarina Maia,Ana Garrido,Isabel Carvalho.Pseudo barter Syndrome as an intial presentations of cystic fibrosis.JNephrol Hyper. 2014;28(4):348-351. 